\title{
Ajustamentos nas agroindústrias de biscoitos e massas alimentícias no Brasil, 1995 a 2001
}

\author{
Sílvio Ferreira Júnior* \\ Marília Fernandes Maciel Gomes**
}

Resumo: Este trabalho objetivou avaliar os ajustamentos ocorridos nos segmentos de biscoitos e massas alimentícias no Brasil, no período de 1995 a 2001, utilizando-se o modelo Estrutura-Conduta-Desempenho, da teoria da Organização Industrial. Os resultados mostram que o novo ambiente competitivo, deflagrado pela desregulamentação setorial e pela abertura comercial, permitiu a intensificação da concorrência e restringiu o poder de mercado das maiores empresas. Os dois segmentos foram obrigados a seguir o processo de adequação às exigências do consumidor, como a melhoria da qualidade, o aumento da variedade e a redução nos preços dos produtos. Todo esse processo foi liderado pelas maiores empresas, que realizaram investimentos em tecnologia e em capacidade produtiva e aumentaram, gradualmente, suas participações no mercado. $\mathrm{O}$ resultado desses ajustamentos traduziu-se, portanto, em melhor desempenho econômico e em maior benefício para a sociedade.

Palavras-chave: Agroindústria, trigo, organização industrial, abertura de mercado.

Classificação JEL: L11, L6.

Abstract: The present work aimed to evaluate the adjustments occurred in the food sector of biscuit and pastry in Brazil, from 1995 to 2001, using

\footnotetext{
*Economista, Mestre em Economia Aplicada e Doutorando em Economia Aplicada (bolsista do CNPq). Departamento de Economia Rural, Universidade Federal de Viçosa. 36571-000 - Viçosa - MG. silviofj@hotmail.com

**Professora doutora do Departamento de Economia Rural, Universidade Federal de Viçosa, bolsista do CNPq, mfmgomes@ufv.br
} 
Ajustamentos nas agroindústrias de biscoitos e massas alimentícias no Brasil, 1995 a 2001

the Structure-Conduct-Performance model of the Industrial Organization theory. The results demonstrated that the new competitive environment, started by the non-regulation in the sector and by the commercial openness, allowed tougher competition and restrained the market power of the major industries. Both segments had to adjust themselves to the demands of the consumer in the market by improving the quality of their products, furnishing a wider variety and reducing their costs. The whole process was led by the major industries, which invested in technology and productive capacity and, continually, increased their participation in the market. Therefore, as a result of these adjustments, there has been an improvement in the economic performance and a greater benefit for society.

Key-word: Agribusiness, wheat, industrial organization, market openness.

JEL Classification: L11, L6

\section{Introdução}

Na década de 1990, o Brasil passou por significativas mudanças em sua economia, as quais contribuíram para modificação do ambiente competitivo da agroindústria de segundo processamento do trigo ${ }^{1}$ no país, aqui representada pelas agroindústrias de biscoitos e massas alimentícias. As regras de livre mercado, o acirramento da concorrência em nível global e a estabilização econômica caracterizam, desde então, esse novo ambiente.

De acordo com Ferreira Júnior (2003), os investimentos para capacitação tecnológica e produtiva, a melhoria da qualidade e o processo de segmentação de mercado (maior variedade de produtos) são as principais estratégias adotadas pelos segmentos em análise, em resposta às mudanças ocorridas no ambiente competitivo, principalmente no que se refere à queda das barreiras à entrada neste mercado após abertura comercial. Essas tendências definem o padrão de concorrência e os novos parâmetros de competitividade, além de evidenciar o empenho destes segmentos para aumentarem a competitividade futura.

Nesse contexto, outra estratégia comum, observada nos segmentos

${ }^{1}$ A agroindústria do trigo inclui os segmentos de primeiro processamento (indústria de moagem do trigo) e segundo processamento (indústrias de massas alimentícias, de biscoitos e de panificação). 
de biscoitos e de massas alimentícias, tem sido a ocorrência de fusões e/ou aquisições, que sugerem processo de concentração de mercado. Segundo Food Ingredients (2002), por constituírem grande número de empresas, com grande heterogeneidade entre si, esses segmentos são, atualmente, os maiores alvos de fusões e aquisições, como alternativa para ampliação de mercado.

Se, por um lado, o processo de concentração possibilita a obtenção de economias de escala e/ou escopo, bem como agilidade no processo de distribuição, por outro, pode criar condições estruturais para que essas grandes empresas exerçam ações prejudiciais à ordem econômica.

No Brasil, a agroindústria de segundo processamento de trigo está inserida num sistema caracterizado como um dos mais tradicionais e estratégicos sistemas agroalimentares do país, atualmente responsável pela produção de parte relevante do consumo de alimentos. O Brasil é o segundo maior produtor mundial de biscoitos, com uma produção de 1.012 mil toneladas e um faturamento de $\mathrm{R} \$ 2.837$ milhões em 2000, ficando atrás dos Estados Unidos, e é o terceiro maior produtor mundial de massas alimentícias, com uma produção de 1.029 mil toneladas e um faturamento de R 1.899 milhão em 2001. Nas primeira e segunda posições estão a Itália e os Estados Unidos, com respectivas produções de 2.900 e 1.160 mil toneladas de massas (SIMABESP, 2002; ABIMA, 2002; Pinazza e Alimandro, 2001).

Em virtude da importância da agroindústria de segundo processamento de trigo no Brasil e das mudanças ocorridas no seu ambiente competitivo, este trabalho teve o objetivo geral de avaliar os ajustamentos ocorridos nos segmentos de massas alimentícias e de biscoitos e bolachas, no período de 1995 a 2001.

\section{Metodologia}

\subsection{Modelo teórico}

Neste trabalho utiliza-se o modelo Estrutura-Conduta-Desempenho (MECD) da teoria da Organização Industrial (OI), proposto por Mason (1939), que admite a hipótese de uma linha de casualidade a partir da estrutura de mercado, passando pela conduta, até o desempenho, for- 
necendo arcabouço de análise mais realista para a maioria dos estudos de organização industrial².

Devem-se considerar, no entanto, os efeitos de feed-back, conforme ilustrado na Figura 1, extraída de Martin (1994).

Figura 1 - interações no modelo estrutura-conduta-desempenho

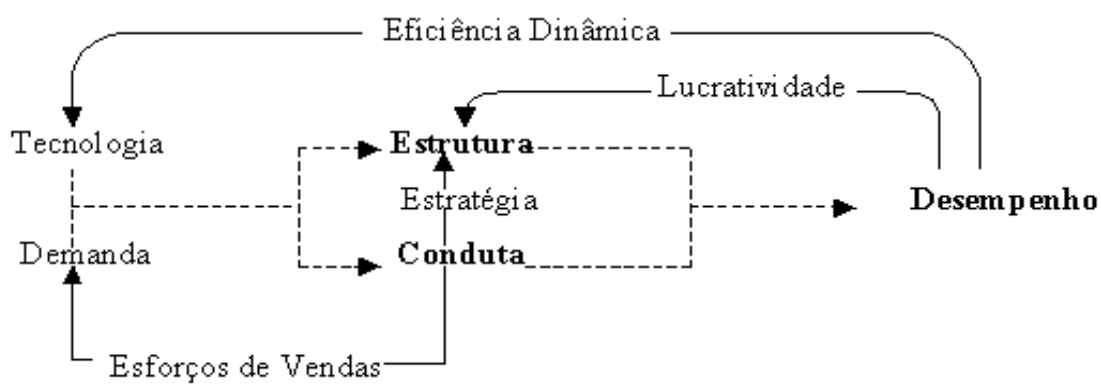

Fonte: Martin (1994).

A Figura 1 mostra, de forma simples e clara, as relações interativas do modelo, a partir das quais o autor denomina de modelo não-linear, no qual estrutura e conduta são determinadas, parcialmente, por condições de demanda e tecnologia. Esforços de venda - um elemento da conduta - afetam, por feedback, a demanda; feedbacks do desempenho impactam a tecnologia e o próprio desempenho; a eficiência dinâmica ou a taxa de progresso tecnológico exerce influência sobre a tecnologia disponível; e a lucratividade, que determina o quanto é atrativo entrar no mercado, tem efeito dinâmico intertemporal sobre a estrutura do mercado.

A análise da estrutura e do desempenho tem sido de grande utilidade à política pública, tendo em vista que o próprio desempenho é definido, no modelo, por alguma idéia de bem-estar econômico, conceituação que instilou na teoria da Organização Industrial uma forte orientação política. Com base na hipótese de concentração-coalizão, caso se verifiquem desempenhos não-satisfatórios, as autoridades governamentais, mediante regulamentação da estrutura e/ou da conduta de mercado, podem alterar o desempenho, com vistas em assegurar um grau mínimo de competição, como, por exemplo, medidas que visam impedir fusões.

${ }^{2}$ Maiores detalhamentos sobre a teoria da OI podem ser encontrados em: Ferreira Júnior (2003), Sherer e Ross (1990), Brumer (1981) e Bain (1968). 


\subsection{Modelo analítico}

Este estudo se concentra na relação estrutura-desempenho, admitindo uma causalidade do primeiro para o último. Apesar de a conduta não ter recebido tratamento explícito, considerações sobre esta estão presentes.

A concentração industrial é a dimensão da estrutura de mercado que, na literatura, tem recebido tratamento mais amplo e detalhado. Teoria e prática sugerem que o caráter, a intensidade e a efetividade da competição entre as empresas são, significativamente, afetados pelo grau de concentração do mercado em que elas atuam (Sherer e Ross, 1990). Assim, utiliza-se neste trabalho o seguinte índice de concentração:

$$
\mathrm{CR}_{\mathrm{m}}=\sum_{\mathrm{i}=1}^{\mathrm{m}} \mathrm{p}_{\mathrm{i}},
$$

em que $\mathrm{m}$ = número de firmas; e Pi = participação da i-ésima firma no faturamento total do segmento em que ela se insere.

Essa medida considera o mesmo grau de importância para todas as firmas e não é afetada pela mudança no número de firmas em uma indústria (Scherer e Ross, 1990). Neste estudo, foram consideradas as participações das quatro e das oito maiores firmas (CR4 e CR8, respectivamente) no faturamento total de cada segmento, nos anos de 1995 a $2001^{3}$.

A análise do desempenho de mercado, por sua vez, requer a utilização de indicadores que levam em conta as características dos segmentos selecionados e as limitações de dados e informações. Desse modo, na análise do desempenho da agroindústria de segundo processamento de trigo no Brasil, foram utilizadas duas categorias de indicadores. A primeira refere-se aos indicadores que refletem o desempenho competitivo de cada segmento como um todo, quais sejam: a) evolução da produção; b) evolução das exportações; c) evolução das importações; d) evolução do faturamento; e e) evolução dos índices reais de preços.

\footnotetext{
${ }^{3}$ Nos cálculos consideram-se as firmas individuais identificadas por sua razão social, e não os grupos empresariais como um todo. Assim, os resultados obtidos podem subestimar a concentração econômica dos segmentos.
} 
Esses indicadores mostram o dinamismo de cada segmento, se está aumentando ou não sua participação na economia, sua competitividade e, indiretamente, sua capacidade de gerar empregos. Adicionalmente, tais indicadores dão sinais que ajudam na avaliação do grau de bem-estar econômico ou da eficiência econômica.

A segunda categoria de indicadores procura refletir o desempenho econômico-financeiro (Assaf Neto, 1998) dos grupos representados pelas oito maiores empresas dos segmentos de massas alimentícias e de biscoitos e bolachas, respectivamente, quais sejam: a) evolução da taxa de lucro sobre o faturamento (L/F); b) evolução da taxa de lucro sobre o ativo total (L/A); c) evolução do faturamento sobre o ativo total (F/A); d) evolução do ativo permanente sobre o ativo total (P/A); e) evolução do endividamento geral (EG); f) evolução da liquidez geral (L); g) evolução do custo de produção sobre o faturamento $(\mathrm{C} / \mathrm{F}) ; \mathrm{h})$ evolução das despesas operacionais gerais sobre o faturamento $(\mathrm{D} / \mathrm{F})$.

Vale lembrar que, por se referirem apenas às maiores empresas, esses indicadores não refletem, necessariamente, o desempenho de cada segmento como um todo. No entanto, certamente eles refletem o desempenho das empresas que compõem grupos estratégicos mais dinâmicos, que investem em diferenciação e segmentação de mercado.

\subsection{Fonte de dados}

Os dados anuais utilizados no cálculo dos índices de concentração e dos indicadores econômico-financeiros abrangem os anos de 1995 a 2001 e foram obtidos do Balanço Anual da Gazeta Mercantil, no site http//:www.gazetamercantil.com.br ${ }^{4}$.

Os dados anuais de importação e exportação foram obtidos na Secretaria de Comércio Exterior (SECEX), nos anos de 1990 a 2001, e estão disponíveis no site http//:aliceweb.mdic.gov.br.

Os dados anuais referentes à produção, ao faturamento e aos índices de preços foram obtidos nas associações de cada indústria ou segmento - Sindicato das Indústrias de Massas e Biscoitos no Estado de São Paulo (Simabesp) e Associação Brasileira da Indústria de Massas (ABIMA).

\footnotetext{
${ }^{4}$ No que se refere aos segmentos da agroindústria do trigo, este site disponibiliza apenas os dados das oito maiores empresas de cada segmento.
} 


\section{Resultados e discussão}

Verificou-se, no período estudado, conforme mostrado na Tabela 1, aumento quase constante no grau de concentração, tanto no segmento de massas alimentícias quanto no de biscoitos. No que se refere ao segmento de massas, as quatro e as oito maiores empresas detinham, respectivamente, $21,56 \%$ e $32,64 \%$ do faturamento do segmento em 1995. Já em 2001, as quatro e as oito maiores empresas passaram a controlar, respectivamente, $35,69 \%$ e $48,52 \%$, do faturamento total. No período, as taxas geométricas de crescimento da concentração, nas quatro e oito maiores empresas, foram de 7,27\% e 5,16\% ao ano, respectivamente.

No segmento de biscoitos, por sua vez, $27,33 \%$ e 33,58\% do faturamento total eram dominados, respectivamente, pelas quatro e pelas oito maiores empresas, em 1995. Já em 2001, as quatro e oito maiores empresas passaram a controlar, respectivamente, $36,77 \%$ e $45,54 \%$ do faturamento total. No período 1995-2001, as taxas geométricas de crescimento dos índices CR4 e CR8 foram de 7,02\% e 6,64\% ao ano, respectivamente.

Tabela 1 - Índices de concentração no segmento de massas alimentícias e de biscoitos

\begin{tabular}{ccccc}
\hline & \multicolumn{2}{c}{ Massas alimentícias } & \multicolumn{2}{c}{ Biscoitos e bolachas } \\
\hline & CR4 & CR8 & CR4 & CR8 \\
\hline 1995 & 0,2156 & 0,3264 & 0,2733 & 0,3358 \\
1996 & 0,2201 & 0,3465 & 0,2366 & 0,3009 \\
1997 & 0,2062 & 0,3316 & 0,2351 & 0,2925 \\
1998 & 0,2243 & 0,3314 & 0,2370 & 0,3029 \\
1999 & 0,2249 & 0,3314 & 0,3246 & 0,3898 \\
2000 & 0,2643 & 0,3868 & 0,3334 & 0,4062 \\
2001 & 0,3569 & 0,4852 & 0,3677 & 0,4554 \\
\hline TGC $^{1}$ & $7,27 \%{ }^{* *}$ & $5,16 \%{ }^{* *}$ & $7,02 \%{ }^{* *}$ & $6,64 \%^{* *}$ \\
\hline
\end{tabular}

Fonte: Dados da pesquisa.

${ }^{1}$ taxa geométrica de crescimento.

** significativo a $5 \%$.

Tanto o segmento de massas alimentícias quanto o de biscoitos e bolachas são constituídos de grande número de empresas, pulverizadas 
e regionalizadas, que apresentam grande heterogeneidade entre si, seja pelo tamanho, seja pelo grau de capacitação tecnológica. O segmento de massas no Brasil era constituído, em 2001, por 802 empresas, grande parte localizada na região Sudeste, $61 \%$ das quais eram de pequeno porte; $22 \%$, médio; e apenas $17 \%$, de grande porte (Pinazza e Alimandro, 2001). O segmento de biscoitos e bolachas, por sua vez, era constituído, naquele ano, por 533 empresas, $40 \%$ das quais estavam localizadas no Estado de São Paulo (SIMABESP, 2002).

A Tabela 2 permite visualizar a evolução de alguns indicadores do desempenho de mercado do segmento de massas alimentícias. No que se refere à produção, percebe-se que houve nítido e contínuo crescimento na quantidade produzida até o ano de 1999, quando se atingiu seu valor máximo de 948 mil toneladas produzidas. A produção naquele ano, quando comparada à de 1994 , revela crescimento da ordem de $24,7 \%$. A taxa geométrica de crescimento, no período 1994-2001, indicou tendência positiva da ordem de $2,70 \%$ ao ano. O período encerrou com 935 mil toneladas produzidas em 2001, com queda de 1,37\%, em relação a 1999.

Tabela 2 - Indicadores de desempenho de mercado no segmento de massas alimentícias

\begin{tabular}{ccccc}
\hline ANO & $\begin{array}{c}\text { Produção } \\
\text { (toneladas) }\end{array}$ & $\begin{array}{c}\text { Exportação } \\
\text { (toneladas) }\end{array}$ & $\begin{array}{c}\text { Importação } \\
\text { (toneladas) }\end{array}$ & $\begin{array}{c}\text { Faturamento } \\
\text { (R\$ milhões) }\end{array}$ \\
\hline 1994 & $760.000,00$ & 790,78 & $12.255,37$ & $2.140,67$ \\
1995 & $850.000,00$ & 866,33 & $21.715,46$ & $2.254,59$ \\
1996 & $860.000,00$ & $1.692,45$ & $22.502,98$ & $2.503,13$ \\
1997 & $920.000,00$ & $1.440,01$ & $25.839,69$ & $2.340,38$ \\
1998 & $929.000,00$ & $1.430,90$ & $28.465,34$ & $2.326,09$ \\
1999 & $948.000,00$ & $1.338,03$ & $20.498,54$ & $2.105,22$ \\
2000 & $936.000,00$ & $1.546,22$ & $16.306,14$ & $1.859,97$ \\
2001 & $935.000,00$ & $1.788,76$ & $14.521,70$ & $1.899,15$ \\
\hline TGC $^{2}$ & $2,70 \%{ }^{* * *}$ & $9,72 \%{ }^{* *}$ & $-0,51 \%{ }^{\mathrm{ns}}$ & $-2,73 \%{ }^{*}$ \\
\hline
\end{tabular}

Fonte: ABIMA (2002), DECEX (2002).

${ }^{1}$ valores reais $(2001=100)$.

${ }^{2}$ Taxa geométrica de crescimento.

*** significativo a $1 \%$; $* *$ significativo a $5 \%$; $*$ significativo a $10 \%$; ns = nãosignificativo. 
No que se refere às importações, verifica-se contínuo crescimento na quantidade importada, que atingiu seu valor máximo em 1998, com, aproximadamente, 28,5 mil toneladas importadas, e revelou crescimento de $132,3 \%$ em comparação ao ano de 1994 . O período encerrou com cerca de 14,5 mil toneladas importadas, em 2001, que corresponde a uma queda de, aproximadamente, 49\% em relação ao ano de 1998. Contribuíram para a queda na quantidade importada a perda de poder aquisitivo da população e a desvalorização cambial. As oscilações verificadas nas importações não permitiram, portanto, verificar tendência significativa de crescimento no período 1994-2001, optando-se pela aceitação da taxa geométrica de crescimento igual a zero.

Quanto à quantidade exportada, observa-se que esta apresentou, a partir de 1996, contínuos decréscimos até o ano de 1999, quando então voltou a crescer, atingindo a maior quantidade exportada do período, cerca de 1.788 toneladas, em 2001. Apesar das oscilações verificadas, as exportações apresentaram tendência positiva de crescimento, da ordem de $9,72 \%$ ao ano, no período de 1994 a 2001.

Apesar de pouco significativo diante do consumo e da produção nacionais, observou-se aumento das importações e das exportações de massas alimentícias, decorrente da maior inserção do Brasil no mercado internacional. De fato, é comum a ocorrência de alianças estratégicas entre empresas brasileiras e argentinas, como alternativa para empresas não-transnacionais explorarem os benefícios da expansão de mercado, proporcionados pelo Mercosul (Azevedo et al., 1998). A associação ocorre entre uma empresa de biscoitos, de um país, e uma de massas, de outro, com o objetivo de utilizar uma rede de distribuição já montada no país importador, permitindo explorar economias de escala técnicas, obtidas da concentração da produção em um só país, e economias de escopo na atividade de distribuição, obtidas pela venda conjunta de massas e biscoitos das duas empresas.

A Tabela 2 permite ainda visualizar a evolução do faturamento no segmento de massas alimentícias, deflacionado pelo IGP-DI no ano de 2001. Percebe-se que o aumento do poder aquisitivo e o aquecimento na demanda no início do Plano Real permitiram que houvesse, no primeiro triênio do período, contínuo aumento no faturamento, que atingiu seu maior valor, da ordem de R \$ 2,5 bilhões, em 1996. No entanto, a 
partir daquele ano, houve queda contínua no faturamento até o ano de 2000, já que seu valor atingiu o mínimo do período, aproximadamente, $\mathrm{R} \$ 1,86$ bilhão. A despeito das oscilações verificadas, o faturamento apresentou tendência significativa e negativa de crescimento, da ordem de $2,73 \%$ ao ano, no período 1994-2001.

No que se refere aos preços, na Figura 2 pode-se observar que, entre julho de 1994 e janeiro de 1998, as massas alimentícias apresentaram tendência de queda nos preços, chegando à redução acumulada de $30 \%$, em termos reais. O comportamento do índice de preços das massas não foi decorrente de queda no preço do trigo em grão; ao contrário, houve, no primeiro semestre de 1996, forte elevação dos preços do trigo, a qual não se traduziu em elevação do preço das massas. Apesar de a Figura 3 não contemplar a evolução dos preços para os anos de 2000 e 2001, é pouco provável que os preços reais tenham aumentado, uma vez que estes anos apresentaram retração no consumo das massas (Ferreira Júnior, 2003).

Figura 2 - Índices reais de preços: trigo e massas alimentícias (IPC-FIPE)

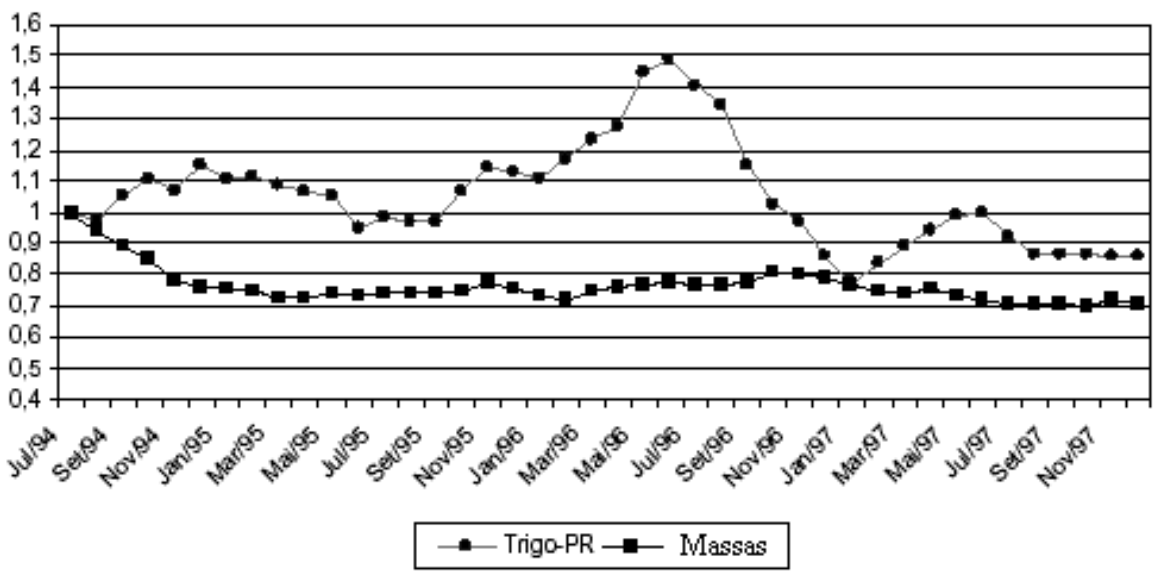

Fonte: Azevedo et al. (1998).

É interessante notar que os preços continuaram em queda mesmo após a implementação do Plano Real, que permitiu incrementos significativos no consumo. Esse fato evidencia a existência de capacidade ociosa neste segmento e a intensificação da concorrência após a abertura comercial. De fato, este segmento trabalha com capacidade ociosa 
em torno de $35 \%$, decorrente do seu processo de reestruturação e de investimentos que procuram antecipar o crescimento da demanda (Azevedo et al., 1998). Ademais, a estabilização econômica beneficiou as empresas deste segmento, na medida em que permitiu melhor controle dos seus custos e melhor planejamento dos seus negócios, podendo refletir no comportamento dos preços reais.

Na Tabela 3 visualiza-se a evolução de alguns indicadores médios do desempenho das oito maiores empresas do segmento de massas alimentícias. A despeito de ter havido aumento no faturamento das maiores empresas, percebe-se tendência de queda contínua e acentuada nos indicadores de rentabilidade das vendas (L/F) e do capital investido (L/A). As taxas geométricas de crescimento desses indicadores revelam quedas expressivas de $29,86 \%$ e $19,76 \%$ ao ano, respectivamente.

A tendência de queda na lucratividade, observada por meio desses dois indicadores, poderia levar a conclusões equivocadas, caso eles não fossem analisados paralelamente a outros indicadores. Assim, é feita, a seguir, a análise dos demais indicadores, que, juntamente com os mencionados anteriormente, permitirão tirar uma conclusão mais precisa acerca do desempenho econômico-financeiro deste segmento.

Quanto ao indicador faturamento líquido sobre o ativo total (F/A), percebe-se que houve queda contínua em todo o período, com exceção de 2001, que apresentou crescimento significativo no seu valor. A taxa geométrica de crescimento desse indicador foi de queda de 1,67\% ao ano, no período. Tal tendência resulta do aumento mais que proporcional dos recursos aplicados (ativo), comparativamente ao aumento do faturamento, o que sugere que há tendência de essas empresas continuarem seguindo a estratégia de crescimento e concentração de mercado.

O comportamento do indicador de capacidade instalada, ou seja, da relação entre o ativo permanente e o ativo total (P/A), não revelou tendência de crescimento, apresentando taxa geométrica de crescimento estatisticamente igual a zero no período. Por conseguinte, pode-se dizer que a capacidade instalada tem crescido na mesma proporção que o crescimento dos recursos totais aplicados na atividade, o que evidencia a tendência dessas empresas em continuarem com a estratégia de crescimento. 
Tabela 3 - Indicadores médios do desempenho das oito maiores empresas no segmento de massas alimentícias

\begin{tabular}{ccccccccc}
\hline ANO & L/F & L/A & F/A & P/A & E.G. & L & C/F & D/F \\
\hline 1995 & 4,95 & 8,18 & 189,04 & 54,39 & 47,83 & 117,73 & 72,15 & 22,74 \\
1996 & 3,23 & 5,63 & 183,51 & 51,93 & 45,54 & 126,55 & 71,46 & 21,69 \\
1997 & 2,73 & 1,68 & 174,65 & 52,31 & 43,43 & 101,08 & 73,03 & 24,59 \\
1998 & 1,51 & 4,21 & 173,61 & 51,56 & 46,38 & 106,37 & 72,20 & 22,48 \\
1999 & 1,77 & 2,96 & 169,99 & 53,30 & 50,50 & 111,10 & 72,22 & 21,56 \\
2000 & 0,68 & 2,38 & 159,64 & 58,10 & 49,11 & 197,18 & 72,11 & 22,61 \\
2001 & 0,59 & 1,54 & 178,92 & 51,08 & 56,99 & 202,44 & 72,81 & 20,71 \\
\hline TGC $^{1}$ & $-29,86^{* * *}$ & $-19,76^{* *}$ & $-1,67^{*}$ & $0,20^{\text {ns }}$ & $3,00^{*}$ & $9,76^{*}$ & $0,12^{\text {ns }}$ & $-1,17^{\text {ns }}$ \\
\hline
\end{tabular}

Fonte: Dados da pesquisa.

${ }^{1}$ taxa geométrica de crescimento.

*** significativo a $1 \%$; ${ }^{* *}$ significativo a $5 \%$; * significativo a $10 \%$; ns = não-significativo.

Quanto à evolução do indicador de endividamento geral (E.G.), apesar das oscilações verificadas no período, seu valor apresentou tendência de crescimento à taxa geométrica de $3,00 \%$ ao ano. Esse fato sugere que o contínuo aumento verificado nos investimentos tem sido financiado, preferencialmente, pelo aumento da participação do capital de terceiros.

Essa situação não se revela arriscada, uma vez que a capacidade média de pagamento das dívidas, tanto no curto como no longo prazo, tem apresentado tendência de crescimento desde 1997, conforme Tabela 3. Essa tendência é verificada pelo aumento no valor do indicador de liquidez geral (L), à taxa geométrica de crescimento de $9,76 \%$ ao ano. $\mathrm{O}$ ano de 2001 apresentou o valor mais alto na liquidez média das maiores empresas, da ordem de $202,44 \%$, o que indica que, para cada unidade monetária de débito total, havia, em média, 2,02 unidades monetárias de ativos circulante e realizável a longo prazo. Pode-se dizer que, dada a estabilização do consumo a partir de 1998, visto que a rentabilidade das vendas e do ativo total se aproximou de zero nos dois últimos anos do período analisado, as maiores empresas optaram por reduzir o crescimento da capacidade produtiva, aumentando a participação do capital de giro nos ativos totais, que, concomitantemente ao aumento mais que proporcional no faturamento, permitiu que houvesse aumento substancial na liquidez.

No que se refere à evolução dos indicadores de custo e despesa, res- 
pectivamente representados pelas relações de custo de produção sobre faturamento líquido $(\mathrm{C} / \mathrm{F})$ e despesas operacionais sobre faturamento líquido $(\mathrm{D} / \mathrm{F})$, percebe-se que eles permaneceram estáveis no período, com ambas as taxas geométricas de crescimento estatisticamente iguais a zero. Por conseguinte, os custos de produção e as despesas operacionais gerais têm crescido na mesma proporção das vendas.

A estabilidade dos índices $\mathrm{C} / \mathrm{F}$ e $\mathrm{D} / \mathrm{F}$ revela-se como fato curioso. A despeito dos ganhos potenciais na produtividade advindos do crescimento das empresas, o processo de melhoria na qualidade, de agregação de valor e de diferenciação dos produtos, conforme verificado por Ferreira Júnior (2003), implica mudança na estrutura de custos das empresas, com aumentos nos custos médios. Esta pode ser uma explicação plausível para a estabilidade do índice C/F, ou seja, o aumento nos custos provenientes de melhoria na qualidade, agregação de valor e diferenciação dos produtos implicou aumento do custo médio na mesma proporção do aumento no faturamento. Considerando-se que a diferença entre o número um (1) absoluto e o índice $\mathrm{C} / \mathrm{F}$ representa o lucro bruto, verifica-se que as maiores empresas têm mantido estável a margem bruta das vendas.

A estabilidade do indicador $\mathrm{D} / \mathrm{F}$ revela que as despesas oriundas da promoção, da distribuição e da venda dos produtos, bem como as despesas de administração dos negócios, têm crescido na mesma proporção do aumento das vendas. De fato, o aumento no tamanho das empresas e o esforço para colocar seus produtos no mercado requerem aumentos nas despesas operacionais. No entanto, verificou-se que estas se mantiveram equilibradas no período.

No que se refere ao segmento de biscoitos e bolachas, o Quadro 4 permite visualizar a evolução de alguns indicadores de desempenho no mercado desse segmento. No tocante à produção, percebe-se que o segmento tem reagido ao aumento verificado na quantidade demandada, visto que houve nítido e contínuo crescimento na quantidade produzida até o ano de 1999, em que atingiu seu valor máximo de 1.089 mil toneladas produzidas. A produção naquele ano, quando comparada à de 1994, revela crescimento da ordem de 44,2\%. Entretanto, a partir daquele ano, a produção sofreu leve retração, encerrando o período com 1,001 mil toneladas produzidas, em 2001. A taxa geométrica de 
crescimento, no período de 1994 a 2001, indicou tendência positiva da produção, da ordem de $3,97 \%$ ao ano.

Quanto às importações, estas chegaram ao patamar mais alto em 1996, com 16 mil toneladas importadas. A quantidade importada naquele ano representou cerca de 5,5 vezes a quantidade importada em 1994. A partir de 1997, no entanto, a quantidade importada sofreu reduções contínuas, com queda acentuada no seu valor após a desvalorização cambial, em 1998, encerrando o período com cerca de 2,2 mil toneladas importadas, em 2001. As oscilações observadas nas importações implicaram uma taxa geométrica de crescimento estatisticamente igual a zero, no período de 1994 a 2001.

Em relação à quantidade exportada, observa-se que, mesmo após a valorização cambial ocorrida em meados de 1994 e final de 1998, as exportações mantiveram-se em crescimento contínuo, o que revela a aceitabilidade do produto nacional pelo mercado externo. Em se tratando do período 1994-2001, as exportações cresceram à taxa geométrica de $26,33 \%$ ao ano.

Tabela 4 - Indicadores de desempenho de mercado

no segmento de biscoitos e bolachas

\begin{tabular}{ccrcc}
\hline Ano & $\begin{array}{c}\text { Produção } \\
\text { (toneladas) }\end{array}$ & $\begin{array}{r}\text { Exportação } \\
\text { (toneladas) }\end{array}$ & $\begin{array}{r}\text { Importação } \\
\text { (toneladas) }\end{array}$ & $\begin{array}{c}\text { Faturamento } \\
\text { (R\$milhões) }\end{array}$ \\
\hline 1994 & $760.000,00$ & $5.340,61$ & $2.893,21$ & $2.459,85$ \\
1995 & $850.000,00$ & $7.249,64$ & $8.975,02$ & $3.175,89$ \\
1996 & $952.000,00$ & $9.286,03$ & $16.010,05$ & $3.405,49$ \\
1997 & $1.003 .000,00$ & $9.782,88$ & $10.370,89$ & $3.486,48$ \\
1998 & $1.068 .000,00$ & $10.136,47$ & $10.358,13$ & $3.990,95$ \\
1999 & $1.089 .000,00$ & $15.036,80$ & $3.165,13$ & $3.394,25$ \\
2000 & $1.012 .000,00$ & $23.585,92$ & $2.135,77$ & $3.131,96$ \\
2001 & $1.001 .000,00$ & $30.733,95$ & $2.239,06$ & $3.393,00$ \\
\hline TGC $^{2}$ & $3,97 \%{ }^{*}$ & $26,33 \%{ }^{* * *}$ & $-15,19 \%{ }^{\mathrm{ns}}$ & $2,78 \%{ }^{\mathrm{ns}}$ \\
\hline
\end{tabular}

Fonte: SIMABESP (2002), DECEX (2002).

${ }^{1}$ valores reais $(2001=100)$.

2 taxa geométrica de crescimento.

*** significativo a $1 \%$; * significativo a $10 \%$; ns = não-significativo. 
A Tabela 4 evidencia ainda que o aumento contínuo da quantidade exportada e a queda na quantidade importada, iniciada antes mesmo da desvalorização cambial, concomitantemente ao aumento verificado na produção, sugerem que o segmento de biscoitos e bolachas tenha se adaptado às novas condições de mercado, revelando-se capaz de atender aos novos padrões de consumo e colocando o Brasil na condição de exportador líquido. As alianças estratégicas entre empresas brasileiras de biscoitos e empresas argentinas de massas explicam, em parte, este resultado ${ }^{5}$.

A Tabela 4 permite visualizar a evolução do faturamento no segmento de biscoitos e bolachas, deflacionados pelo IGP-DI no ano de 2001. Podese dizer que o aumento do poder aquisitivo e o aquecimento na demanda permitiram que houvesse contínuo aumento no faturamento até o ano de 1998, em que se atingiu seu maior valor, aproximadamente, R 3.991 milhões. A partir daquele ano, houve queda contínua no faturamento até o ano de 2000, quando seu valor ficou em torno de R 3.132 milhões.

No que se refere aos preços, pode-se observar na Figura 3 que, de julho de 1994 a janeiro de 1998, os biscoitos mais populares (água e $\mathrm{sal} /$ maisena) e os recheados apresentaram redução da ordem de 43,0\% e $34,6 \%$ nos preços, respectivamente, enquanto os biscoitos ao leite (mais sofisticados) tiveram queda de $16,0 \%$ nos preços.

Figura 3 - Índices reais de preços: biscoitos (IPC-FIPE)

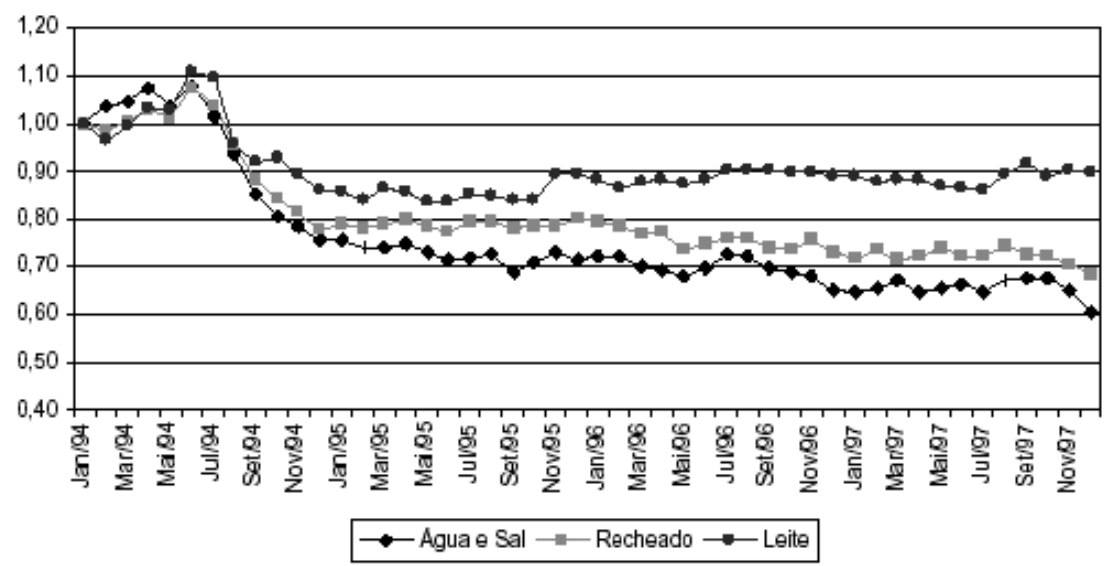

Fonte: AZEVEDO et al. (1998).

${ }^{5}$ Maiores informações, ver Ferreira Júnior (2003). 
É interessante notar que os preços dos biscoitos tiveram queda mesmo após a implementação do Plano Real, pelos mesmos motivos verificados no segmento de massas, quais sejam, existência de capacidade ociosa e intensificação da concorrência.

A Figura 3 permite visualizar que, a partir de 1996, enquanto os preços dos biscoitos água \& sal e recheados continuaram apresentando tendência de queda, os preços dos biscoitos ao leite se estabilizaram, o que evidencia a diferenciação destes, aos olhos do consumidor. De modo semelhante ao verificado no segmento de massas, é pouco provável que os preços reais dos biscoitos tenham aumentado, uma vez que o consumo destes ficou estagnado a partir de 1999 (Ferreira Júnior, 2003).

A Tabela 5 permite visualizar a evolução de alguns indicadores médios do desempenho das oito maiores empresas do segmento de biscoitos e bolachas. A despeito de ter havido aumento no faturamento das maiores empresas, percebe-se tendência de queda nos indicadores de rentabilidade das vendas $(\mathrm{L} / \mathrm{F})$ e do capital investido (L/A). As taxas geométricas de crescimento desses indicadores revelam quedas de $16,03 \%$ e $23,48 \%$ ao ano, respectivamente, comportamento que é melhor compreendido após a análise dos demais indicadores, conforme visto a seguir.

Quanto ao indicador faturamento líquido sobre o ativo total (F/A), percebe-se que, apesar das oscilações ocorridas no início do período, houve, a partir de 1998, queda contínua e acentuada no seu valor, apresentando o menor valor do período em 2001, da ordem de $115,68 \%$. A taxa geométrica de crescimento desse indicador foi de queda de 4,71\% ao ano, no período. De modo semelhante ao verificado no segmento de massas alimentícias, essa tendência resulta no aumento mais que proporcional dos recursos aplicados, comparativamente ao aumento do faturamento, o que sugere que haja tendência de essas empresas continuarem seguindo a estratégia de crescimento.

O comportamento do indicador de capacidade instalada (P/A) revelou tendência de crescimento no período, à taxa geométrica de 1,28\% ao ano. Por conseguinte, evidencia-se que a capacidade instalada tem crescido mais que proporcionalmente ao crescimento dos recursos totais aplicados na atividade, o que corrobora a afirmativa de que as maiores empresas do segmento de biscoitos e bolachas continuarão seguindo a estratégia de crescimento. 
Tabela 5 - Indicadores médios do desempenho das oito maiores empresas no segmento de biscoitos e bolachas

\begin{tabular}{ccccccccc}
\hline ANO & L/F & L/A & F/A & P/A & E.G. & L & C/F & D/F \\
\hline 1995 & 13,94 & 11,13 & 146,71 & 48,72 & 37,53 & 250,15 & 68,79 & 24,45 \\
1996 & 11,79 & 22,99 & 166,39 & 46,23 & 34,37 & 284,94 & 64,42 & 29,08 \\
1997 & 9,75 & 8,50 & 144,93 & 50,09 & 32,93 & 232,92 & 60,10 & 27,33 \\
1998 & 10,42 & 8,25 & 148,06 & 51,41 & 35,68 & 255,99 & 65,87 & 30,55 \\
1999 & 5,65 & 4,14 & 132,61 & 49,31 & 41,47 & 185,21 & 64,39 & 28,92 \\
2000 & 6,50 & 3,87 & 126,50 & 50,47 & 43,11 & 182,90 & 60,87 & 29,72 \\
2001 & 4,86 & 2,61 & 115,68 & 52,01 & 44,69 & 189,47 & 69,26 & 28,51 \\
\hline TGC $^{1}$ & $-16,03^{* * *}$ & $-23,48^{* * *}$ & $-4,71^{* * *}$ & $1,28^{*}$ & $4,41^{* *}$ & $-6,73^{* * *}$ & $-0,09^{\text {ns }}$ & $-2,02^{\text {ns }}$ \\
\hline
\end{tabular}

Fonte: Dados da pesquisa.

${ }^{1}$ taxa geométrica de crescimento.

***significativo a $1 \%$; ** significativo a $5 \%$; *significativo a $10 \%$; ns = não-significativo.

Quanto à evolução do indicador de endividamento geral (E.G.), apesar de o seu valor ter caído no primeiro triênio do período, ele apresentou tendência contínua de crescimento a partir de 1997, o que contribuiu para o valor da taxa geométrica de crescimento de $3,00 \%$ ao ano, em todo o período. Esse fato evidencia que o contínuo aumento verificado nos investimentos tem sido financiado, preferencialmente, pelo aumento da participação do capital de terceiros.

O aumento do endividamento tem sido acompanhado pela tendência de queda da capacidade média de pagamento das dívidas, tanto no curto como no longo prazo. Percebe-se na Tabela 5 que, apesar das oscilações verificadas, o valor do indicador de liquidez geral (L) caiu à taxa geométrica de crescimento de $6,73 \%$ ao ano.

Essa evidência pode ser explicada pelo fato de que este grupo apresentou maiores taxas de rentabilidade e menores índices de endividamento, quando comparado ao do segmento de massas alimentícias, razão por que esses números não revelam risco de insolvência. Em 2001, por exemplo, as rentabilidades das vendas e do ativo foram, respectivamente, de 4,27 e 2,35 pontos percentuais acima das rentabilidades do grupo do segmento de massas alimentícias, enquanto o endividamento geral daquele grupo encerrou 2001 com valor de 12,30 pontos percentuais abaixo do grupo do segmento de massas.

Quanto à evolução dos indicadores de custo e despesa (C/F e D/F), percebe-se que eles permaneceram estáveis, visto que ambas as taxas 
Ajustamentos nas agroindústrias de biscoitos e massas alimentícias no Brasil, 1995 a 2001

geométricas de crescimento foram estatisticamente iguais a zero, no período. Por conseguinte, os custos de produção e as despesas operacionais gerais têm crescido na mesma proporção das vendas. A explicação provável para esse comportamento é a mesma observada no segmento de massas alimentícias, qual seja, mudança na estrutura de custos resultante do processo de melhoria na qualidade, de agregação de valor e de diferenciação dos produtos, bem como aumento nas despesas de administração e de vendas inerentes à empresa que opta pelo crescimento.

\section{Conclusões}

O novo ambiente competitivo da agroindústria de segundo processamento do trigo no Brasil, caracterizado pela abertura comercial, traduziu-se na queda das barreiras ao mercado doméstico de massas alimentícias e de biscoitos, o que permitiu a intensificação da concorrência e restringiu, significativamente, o poder das grandes empresas em controlar os preços dos seus produtos. Os dois segmentos passam por rápido processo de concentração de mercado, já que as maiores empresas lideram os processos de investimentos em tecnologia e capacidade produtiva - o que permite a obtenção de economias de escala e escopo - e de diversificação e qualidade dos produtos, caracterizando novos parâmetros de concorrência extra preço. Os resultados desses ajustamentos têm se traduzido, até o momento, em melhor desempenho econômico e maior benefício para a sociedade.

\section{Referências bibliográficas}

ASSOCIAÇÃO BRASILEIRA DAS INDÚSTRIAS DE MASSAS ALIMENTÍCIAS ABIMA. Informações sobre o setor de massas alimentícias brasileiro. Disponível em: http://www.abima.com.br. Acesso: 01 ago 2002.

ASSAF NETO, A. Estrutura e análise de balanços: um enfoque econômico-financeiro. São Paulo: Atlas, 1994. 292 p.

AZEVEDO, P.F., GIORDANO, S. R., BORRÁS, M. A. Competitividade do sistema agroindustrial do trigo. In: FARINA, E.M.M.Q., ZYLBERSZTAJN, D. (Coord.). Competitividade no agribusiness brasileiro. São Paulo: PENSA/FIA/FEA/ USP, v. 2, p. 1-177, 1998. 
BAIN, J.S. Industrial organization. 2.ed. New York: John Wiley \& Sons, 1968. $126 \mathrm{p}$.

BRUMER, S. Estrutura, conduta e desempenho de mercado na indústria metal - mecânica gaúcha - 1977. Porto Alegre: Fundação de Economia e Estatística, 1981. 163 p.

FERREIRA JÚNIOR, S. Ajustamentos na agroindústria de segundo processamento de trigo no Brasil, de 1995 a 2001. Viçosa, MG: UFV, Imprensa Universitária, 2003. 80 f. Dissertação (Mestrado em Economia Aplicada) - Universidade Federal de Viçosa, Viçosa.

FOOD INGREDIENTS. Pesquisa e desenvolvimento na indústria de alimentos e bebidas. v. 19, n. 4, p. 26-36, 2002.

MARTIN, S. Industrial economics: economic analysis and public policy. New Jersey: Prentice Hall, 1994.

MASON, E.S. Price and production policies of large scale enterprise. American Economic Review, v. 29, p. 61-74, 1939.

PINAZZA, L.A., ALIMANDRO, R. Otimismo contido. Agroanalysis, v. 21, n. 12 , p. 38-42, 2001.

SCHERER, F.M., ROSS, D. Industrial market structure and economic performance. 3.ed. Boston: Houghton Mifflin Company, 1990.

SECRETARIA DO COMÉRCIO EXTERIOR - SECEX. Dados estatísticos de comércio. Disponível em: http://aliceweb.mdic.gov.br. Acesso: 01 ago 2002.

SINDICATO DAS INDÚSTRIAS DE MASSAS E BISCOITOS NO ESTADO DE SÃO PAULO - SIMABESP. Estatística. Disponível em: http://www.simabesp.org.br. Acesso: 01 ago 2002.

Recebido em abril de 2004 e revisto em março de 2006 